Background: The COVID-19 pandemic has disrupted healthcare delivery and education of physicians, including rheumatology trainees.

Objectives: To assess the impact of the COVID-19 pandemic on the clinical experiences, research opportunities, and well-being of rheumatology trainees. Methods: A voluntary, anonymous, web-based survey was administered in English, Spanish, or French from 19/08/2020 to 05/10/2020. Adult and paediatric rheumatology trainees worldwide in training in 2020 were invited to participate via social media and email. Using multiple choice questions, Likert scales, and free text answers, we assessed trainee patient care activities, redeployment, research, and well-being.

Results: The 302 respondents were from 33 countries, with most (83\%, $252 / 302)$ in adult rheumatology training. Many trainees $(45 \%, 135 / 300)$ reported an increase in non-rheumatology clinical work (e.g. care of COVID-19 patients), with $52 \%$ of these $(70 / 135)$ also continuing rheumatology clinical work. COVID19 redeployment was not optional for $68 \%(91 / 134)$.

Trainees reported a negative impact of the pandemic in their growth in rheumatology (Figure 1). They also reported a substantial impact on several training areas: outpatient clinics $(79 \%, 238 / 302)$, inpatient consultations $(59 \%, 177 / 302)$, formal teaching $(55 \%, 167 / 302)$, procedures $(53 \%, 147 / 302)$, teaching opportunities $(52 \%, 157 / 302)$, and ultrasonography $(36 \%, 110 / 302)$, with $87-96 \%$ perceiving a negative impact on these areas. Only 54\% (159/294) reported feeling comfortable with their level of clinical supervision during the pandemic (Figure 1). Many trainees $(46 \%, 128 / 280)$ reported changes in research experiences during the pandemic; $39 \%(110 / 285)$ reported that COVID-19 negatively affected their ability to continue their pre-pandemic research and 50\% (142/285) reported difficulty maintaining research goals (Figure 1)

Some rheumatology trainees reported having health condition(s) putting them at high risk for COVID-19 $(10 \%, 30 / 302)$ and $14 \%$ of trainees $(41 / 302)$ reported having had COVID-19 (Table 1). Only 53\% (160/302) reported feeling physically safe in the workplace while $25 \%$ (76/302) reported not feeling physically safe; reasons included lack of training about COVID-19, lack of comfort in the clinical setting, insufficient personal protective equipment, immunocompromised state, and pregnancy. Half (151/302) reported burnout and 68\% (204/302) an increase in stress from work during the pandemic (Figure 1), whilst $25 \%(75 / 302)$ reported that changes to their training programme negatively impacted their physical health.

Conclusion: The COVID-19 pandemic has negatively impacted the experience of rheumatology training as well as the well-being of trainees globally. Our data highlight concerns for rheumatology trainees including research opportunities and clinical care which should be a focus for curriculum planning.

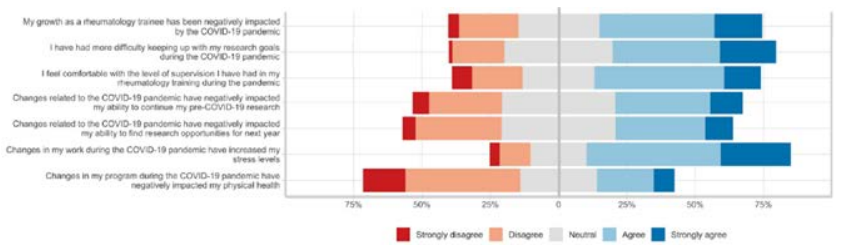

Figure 1. Rheumatology trainee perceptions of pandemic impact and changes in training programme.

Table 1. Rheumatology trainees reporting health vulnerabilities or having acquired COVID-19. Data is presented as $\mathrm{n}(\%)$. Rest of the world (ROW) data includes the United States (116), Asia (50), Central and South America (23), Canada (12), Australia (8), and Africa (4).

\begin{tabular}{lccc}
\hline & $\begin{array}{c}\text { Europe } \\
\mathrm{n}=89\end{array}$ & $\begin{array}{c}\mathrm{ROW} \\
\mathrm{n}=213\end{array}$ & $\begin{array}{c}\text { Combined } \\
\mathrm{n}=302\end{array}$ \\
\hline Disability & $1(1)$ & $9(4)$ & $10(3)$ \\
High risk & $7(8)$ & $23(11)$ & $30(10)$ \\
Pregnant & $4(5)$ & $15(7)$ & $19(6)$ \\
Shielding/Quarantining & $12(13)$ & $70(33)$ & $82(27)$ \\
Acquired COVID-19 & $20(22)$ & $21(10)$ & $41(14)$
\end{tabular}

Disclosure of Interests: Kristen Young: None declared, Su-Ann Yeoh: None declared, Michael Putman: None declared, Elizabeth Graef: None declared, Francis Berenbaum: None declared, Richard Conway: None declared, Rebecca Grainger Speakers bureau: Speaker fees from Abbvie, Janssen, Novartis, Pfizer, Cornerstones, all not related to this work, Consultant of: Consultancy fees from Abbvie, Janssen, Novartis, Pfizer, Cornerstones, all not related to this work, Grant/research support from: Travel assistance from Pfizer, not related to this work, Adam Kilian: None declared, Maximilian Konig: None declared, Jean Liew Grant/research support from: Research grant from Pfizer unrelated to this manuscript, Pedro M Machado Speakers bureau: Speaker fees from Abbvie, BMS, Celgene, Eli Lilly, Janssen, MSD, Novartis, Orphazyme, Pfizer, Roche and UCB, all unrelated to this manuscript, Consultant of: Consulting fees from Abbvie, BMS, Celgene, Eli Lilly, Janssen, MSD, Novartis, Orphazyme, Pfizer, Roche and UCB, all unrelated to this manuscript, Sebastian E. Sattui: None declared, Jeffrey Sparks Consultant of: Consultancy for Bristol-Myers Squibb, Gilead, Inova Diagnostics, Optum, and Pfizer unrelated to this manuscript Grant/research support from: Research support from Bristol-Myers Squibb unrelated to this manuscript, Paul Sufka: None declared, Manuel Ugarte-Gil Grant/research support from: Research grants from Janssen and Pfizer unrelated to this manuscript, Laura Upton: None declared, Zachary Wallace: None declared, Jinoos Yazdany Consultant of: Consultancy for Astra Zeneca, Eli Lilly, and Pfizer, not related to this work, Grant/research support from: Research grants from Gilead and Pfizer, not related to this work, Arundathi Jayatilleke: None declared.

DOI: 10.1136/annrheumdis-2021-eular.2236

\section{POS0052 PATHOPHYSIOLOGY OF ACUTE RESPIRATORY SYNDROME CORONAVIRUS 2 INFECTION: A SYSTEMATIC LITERATURE REVIEW TO INFORM EULAR POINTS TO CONSIDER}

A. Najm ${ }^{1}$, A. Alunno ${ }^{2}$, X. Mariette ${ }^{3}$, B. Terrier ${ }^{4}$, G. De Marco ${ }^{5}$, L. Mason ${ }^{6}$, J. Emmel ${ }^{6}$, D. Mcgonagle ${ }^{5}$, P. M. Machado ${ }^{7}$ on behalf of EULAR Task Force on pathophysiology and use of immunomodulatory therapies in COVID-19.. ${ }^{1}$ Institute of Infection, Immunity and Inflammation, College of Medical Veterinary and Life Sciences, Rheumatology, Glasgow, United Kingdom; ${ }^{2}$ University of Perugia, Rheumatology, Perugia, Italy; ${ }^{3}$ Paris-Saclay University, Rheumatology, Paris, France; ${ }^{4}$ University of Paris, Assistance Publique-Hôpitaux de Paris, Cochin Hospital, INSERM U970, Paris, France; ${ }^{5}$ Leeds Institute of Rheumatic and Musculoskeletal Medicine, Rheumatology, Leeds, United Kingdom; ${ }^{6}$ Library \& Evidence Research Centre, Leeds Teaching Hospitals NHS Trust, Medical Education, Leeds, United Kingdom; ${ }^{7}$ Centre for Rheumatology \& Department of Neuromuscular Diseases, University College London, Rheumatology, London, UK, United Kingdom

Background: The severe acute respiratory syndrome coronavirus 2 (SARSCoV-2) pandemic is a global health problem. Beside the specific pathogenic effect of SARS-CoV-2, incompletely understood deleterious and aberrant host immune responses play critical roles in severe disease. Rheumatologists have the best experience of studying and treating these complicated hyperinflammatory processes.

Objectives: To summarize the available information on pathophysiology of COVID-19.

Methods: As part of a EULAR taskforce, two systematic literature reviews were performed one on pathophysiology and one on immunomodulatory therapies. Two reviewers independently identified eligible studies according to the following PICO framework: P (population): patients with SARS-CoV-2 infection; I (intervention): any intervention/no intervention; C (comparator): any comparator; $\mathrm{O}$ (outcome) any clinical or serological outcome including but not limited to immune cell phenotype and function and serum cytokine concentration. The results pertaining to pathophysiology of COVID-19 are presented here.

Results: Of the 55496 records yielded, 85 articles were eligible for inclusion. Included studies were at variable risk of bias and exploring various aspects of disease pathogenesis from immune to non-immune cells (Table 1). Pro-inflammatory cytokines' expression including IL-6, was increased, especially in severe COVID-19, although not as high as other states with severe systemic inflammation. Innate and adaptative immune cell compartments were differentially affected by SARS-CoV-2 infection: neutrophils displayed an immature differentiation state and also increased neutrophil extracellular traps (NETs) formation. Dendritic cell number was reduced and classical monocytes was increased although displaying a reduced expression of HLA-DR. The lymphoid compartment was also affected: lymphopenia was present with a reduced number of CD4+ and CD8+ T lymphocytes and more frequent PD1+CD8+ T cells corresponding to an exhausted phenotype. Antibody response to SARS-CoV-2 infection showed a high variability across individuals and disease spectrum. Multiparametric algorithms showed variable diagnostic performances in predicting survival, hospitalization, disease progression or severity, and mortality. Differences in SARS-CoV-2 manifestations in adults and children were highlighted.

Conclusion: Overall, SARS-CoV-2 infection affects both innate and adaptative immune responses in a variable way, according to both disease severity and individual parameters. This SLR informs the EULAR points to consider on pathophysiology and use of immunomodulatory therapies in COVID-19. 
Table 1. Studies on SARS-CoV-2 infection pathogenesis

\begin{tabular}{lc}
\hline Research question & $\mathrm{N}$ \\
\hline Cytokines profile & 7 \\
Immune profile & 18 \\
Algorithm & 17 \\
Children & 3 \\
Comorbidities & 1 \\
Endothelial dysfunction and platelets & 8 \\
Gut and microbiota & 3 \\
Genetics and variants & 8 \\
Histology & 7 \\
Antibodies profiles & 8 \\
Viral load and immune response & 4 \\
Interferon & 3 \\
Immunosenecsnce & 3 \\
Total & $90^{\star}$ \\
\end{tabular}

*Some manuscripts were including in several research questions. Total number of studies included $\mathrm{n}=85$.

Disclosure of Interests: Aurelie Najm Speakers bureau: BMS, Consultant of: BMS, Alessia Alunno: None declared, Xavier Mariette Speakers bureau: BMS, Eli Lilly, Galapagos, Gilead, GSK, Janssen, Novartis, Pfizer, Servier and UCB, Consultant of: BMS, Eli Lilly, Galapagos, Gilead, GSK, Janssen, Novartis, Pfizer, Servier and UCB, Benjamin Terrier Speakers bureau: Roche, Chugai, Vifor Pharma, GSK, AstraZeneca, Terumo BCT, LFB and Grifols, Consultant of: Roche, Chugai, Vifor Pharma, GSK, AstraZeneca, Terumo BCT, LFB and Grifols, Gabriele De Marco: None declared, Laura Mason: None declared, Jenny Emmel: None declared, Dennis McGonagle Speakers bureau: Abbvie, BMS, Celgene, Eli Lilly, Janssen, MSD, Novartis, Pfizer, Roche and UCB, Consultant of: Abbvie, BMS, Celgene, Eli Lilly, Janssen, MSD, Novartis, Pfizer, Roche and UCB, Pedro M Machado Speakers bureau: Abbvie, BMS, Celgene, Eli Lilly, Janssen, MSD, Novartis, Orphazyme, Pfizer, Roche and UCB, Consultant of: Abbvie, BMS, Celgene, Eli Lilly, Janssen, MSD, Novartis, Orphazyme, Pfizer, Roche and UCB.

DOI: 10.1136/annrheumdis-2021-eular.2851

\section{POS0053 RHEUMATOID ARTHRITIS AND THE RISK OF COVID- 19 DIAGNOSIS, HOSPITALISATION AND DEATH: A POPULATION-BASED MULTI-STATE COHORT ANALYSIS INCLUDING 5,586,565 PEOPLE IN CATALONIA, SPAIN}

A. Vivekanantham ${ }^{1,2}$, E. Burn ${ }^{1,3}$, S. Fernandez-Bertolin3, M. Aragon3, T. Duarte-Salles3, D. Prieto-Alhambra ${ }^{1,4}$. ${ }^{1}$ University of Oxford, Centre for Statistics in Medicine, Nuffield Department of Orthopaedics, Rheumatology, and Musculoskeletal Sciences, Oxford, United Kingdom; ${ }^{2}$ Nuffield Orthopaedic Centre, Rheumatology, Oxford, United Kingdom; ${ }^{3}$ Fundació Institut Universitari per a la recerca a l'Atenció Primària de Salut Jordi Gol i Gurina, (IDIAPJGol), Barcelona, Spain; ${ }^{4}$ Erasmus University Medical Center, Health Data Sciences, Rotterdam, Netherlands

Background: The COVID-19 pandemic caused by the severe acute respiratory syndrome coronavirus 2 (SARS-CoV-2) virus is of particular concern for people with rheumatoid arthritis (RA), with concerns that these people may be at higher risk and have poorer outcomes. However, at present the implications of COVID19 for people with RA remain poorly understood.

Objectives: To investigate the associations between rheumatoid arthritis and the risk of COVID-19 diagnosis, hospitalisation with COVID-19 and COVID-19-related death.

Methods: A population-based cohort study including all individuals registered in the Information System for Research in Primary Care (SIDIAP). SIDIAP includes primary care records covering over $80 \%$ of the population of CataIonia, Spain, and was linked to region-wide SARS-CoV-2 PCR testing, hospital and mortality records. Outpatient diagnoses of COVID-19, hospitalisations with COVID-19 and deaths with COVID-19 were identified as study outcomes between 1st March and 6th May 2020. A multi-state model was used, with cause-specific Cox survival models estimated for each transition, adjusted for age and sex.

Results: A total of 5,586,565 individuals were identified in SIDIAP as of the $1^{\text {st }}$ March 2020, of which 16,344 had RA. RA patients were median (IQR) 63 years $(52.0,74.0)$ and the majority $(n=11,727,71.8 \%)$ were female. Having RA was positively associated with being diagnosed with COVID-19 (adjusted HR 1.14 (1.03 to 1.28)), with hospitalisation with COVID-19 (HR 1.66 (1.35 to 2.04)). However, we did not find an association between RA status and the risk of worsening from outpatient diagnosis to hospitalization or death, or from hospitalization to death (see Table 1).
Table 1. Estimated hazard ratios, adjusted for age and gender, for individuals with rheumatoid arthritis

\begin{tabular}{|c|c|c|c|}
\hline Transition & $\begin{array}{l}\text { Study population } \\
\text { (RA), n }\end{array}$ & $\begin{array}{l}\text { Total events } \\
\text { (RA), } \mathrm{n}\end{array}$ & $\begin{array}{l}\text { Hazard Ratios } \\
\text { (95\% Confidence } \\
\text { Intervals) }\end{array}$ \\
\hline $\begin{array}{l}\text { From general population to diag- } \\
\text { nosed with COVID-19 }\end{array}$ & $5,586,565(16,344)$ & $88,396(324)$ & 1.14 (1.03 to 1.28$)$ \\
\hline $\begin{array}{l}\text { From general population to hospi- } \\
\text { talised with COVID-19 }\end{array}$ & $5,586,565(16,344)$ & $10,143(90)$ & 1.66 (1.35 to 2.04$)$ \\
\hline $\begin{array}{l}\text { From diagnosed with COVID-19 to } \\
\text { hospitalised with COVID-19 }\end{array}$ & $88,396(324)$ & $5,946(30)$ & 0.95 (0.66 to 1.36$)$ \\
\hline $\begin{array}{l}\text { From diagnosed with COVID-19 } \\
\text { to death }\end{array}$ & $88,396(324)$ & 2,295 (16) & 0.96 (0.58 to 1.56$)$ \\
\hline $\begin{array}{l}\text { From hospitalised with COVID-19 } \\
\text { to death }\end{array}$ & $16,089(120)$ & $2,602(27)$ & 1.13 (0.77 to 1.64$)$ \\
\hline
\end{tabular}

Conclusion: To our knowledge, this is the largest study performed to date looking at COVID-19 outcomes in RA patients. Individuals with RA were found to have an increased risk of COVID-19 diagnosis and hospitalisation with COVID-19, compared to the general population. Further research is needed to address factors associated with this including the presence of other co-morbidities, underlying RA disease activity and the use of immunosuppressive medications.

Disclosure of Interests: Arani Vivekanantham: None declared, Edward Burn: None declared, Sergio Fernandez-Bertolin: None declared, Maria Aragon: None declared, Talita Duarte-Salles: None declared, Daniel Prieto-Alhambra Grant/research support from: Dr. Prieto-Alhambra reports grants and other from AMGEN, grants, non-financial support and other from UCB Biopharma, grants from Les Laboratoires Servier, outside the submitted work; and Janssen, on behalf of IMI-funded EHDEN and EMIF consortiums, and Synapse Management Partners have supported training programmes organised by DPA's department and open for external participants

DOI: 10.1136/annrheumdis-2021-eular.3160

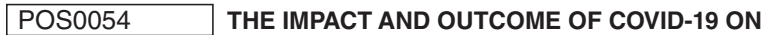 SYSTEMIC SCLEROSIS PATIENTS FROM THE EUROPEAN SCLERODERMA TRIAL AND RESEARCH GROUP (EUSTAR)}

A. M. Hoffmann-Vold ${ }^{1}$, C. Brunborg ${ }^{2}$, F. Tirelli ${ }^{3}$, P. Carreira ${ }^{4}$, N. Del

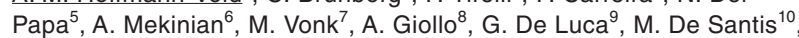
C. Campochiaro ${ }^{9}$, C. Mihai ${ }^{3}$, P. Airò ${ }^{11}$, M. G. Lazzaroni ${ }^{11}$, E. Zanatta ${ }^{12}$, R. Foti ${ }^{13}$, Y. Allanore ${ }^{14}$, D. Furst ${ }^{15}$, M. Matucci-Cerinic ${ }^{16}$, A. Gabrielli ${ }^{17}$, O. Distler ${ }^{3}$. ${ }^{1}$ Oslo University Hospital, Rheumatology, Oslo, Norway; ${ }^{2}$ Oslo University Hospital, Centre for Biostatistics and Epidemiology, Research Support Services, Oslo, Norway; ${ }^{3}$ University Hospital Zurich, University of Zurich, Rheumatology, Zurich, Switzerland; ${ }^{4} 12$ de Octubre University Hospital, Rheumatology, Madrid, Spain; ${ }^{5}$ ASST G. Pini-CTO, University of Milan, Rheumatology, Milan, Italy; ${ }^{6}$ Hôpital Saint Antoine, Internal Medicine, Paris, France; ${ }^{7}$ Radboud University Medical Center, Rheumatology, Nijmegen, Netherlands; ${ }^{8}$ University of Verona, Rheumatology, Verona, Italy; ${ }^{9}$ RCCS San Raffaele Hospital, Vita-Salute San Raffaele University, Immunology, Rheumatology, Allergy and Rare Diseases, Milan, Italy; ${ }^{10}$ IRCCS Humanitas Research Hospital, Rheumatology and Clinical Immunology, Milan, Italy; ${ }^{11}$ ASST Spedali Civili of Brescia, Rheumatology and Clinical Immunology, Brescia, Italy; ${ }^{12}$ University of Padova,

Rheumatology, Padova, Italy; ${ }^{13}$ A.O.U. Policlinico S. Marco, Rheumatology, Catania, Italy; ${ }^{14}$ Cochin Hospital, Université de Paris, Rheumatology, Paris, France; ${ }^{15}$ University of California in Los Angeles, Rheumatology, Los Angeles, United States of America; ${ }^{16}$ University of Florence, Rheumatology, Florence, Italy; ${ }^{17}$ Università Politecnica delle Marche, Scienze Cliniche e Molecolari, Ancona, Italy

Background: Coronavirus disease-19 (COVID-19) has been a major clinica challenge worldwide. Sex, age and comorbidities have been associated with worse outcome in the general population. Systemic sclerosis (SSc) is a severe, autoimmune disease with frequent multi-organ involvement.

Objectives: To assess the impact of COVID-19 and to determine factors associated with worse outcome in SSc patients from the European Scleroderma Trial and Research (EUSTAR) database.

Methods: SSc patients from the EUSTAR database with COVID-19 were prospectively collected between 15.03.-31.12.2020. Two outcomes were chosen: (1) hospitalization; and (2) severe outcome defined as either non-invasive ventilation, mechanical ventilation/extracorporeal membrane oxygenation (ECMO) or death. General risk factors assessed were sex, age and number 